\title{
De Gerchunoff a Kosher Waters: cómo se legitimaron los judíos en la Argentina
} (1910-2010)

From Gerchunoff to Kosher Waters: how the Jews were legitimized in Argentina (1910-2010)

\author{
Ivan Cherjowsky \\ Universidad Nacional de Quilmes \\ Universidad Abierta Interamericana \\ Argentina \\ ivancherj@yahoo.com.car
}

\section{Resumen}

El artículo revisa cinco estrategias puestas en práctica por distintos actores de la colectividad judía argentina con el objetivo de legitimarse socialmente entre el centenario y el bicentenario del país. De este modo, se propone la hipótesis de que la legitimidad es la resultante de un proceso complejo, que involucra la elaboración de políticas específicas por parte de intelectuales, artistas y líderes comunitarios.

Palabras clave: legitimación, memoria, comunidad judía argentina.

"From Gerchunoff to Kosher Waters: how Jews were legitimized in Argentina (19102010)"

\begin{abstract}
This article reviews five strategies developed by different actors of the Argentine Jewish community between the centenary and the bicentennial of the country, in order to obtain social legitimization. In this way, the hypothesis proposed sugest that legitimacy is the result of a complex process which involves the elaboration of specific policies on the part of intellectuals, artists and community leaders.
\end{abstract}

Key words: legitimation, memory, argentinian Jewish community. 


\section{Introducción}

En On Modern Jewish Politics (1993), el historiador norteamericano Ezra Mendelsohn identifica tres tipos de políticas orientadas a resolver el problema de la continuidad del judaísmo en el mundo moderno y secular: el nacionalismo, que implica la construcción de una sociedad judía independiente, sea en su versión autonomista o soberana; la ortodoxia, que conlleva la idea del rechazo a la modernidad más el refuerzo de los lazos primordiales y del límite étnico (Barth, 1976); y el liberalismo, encarnado en la idea de adoptar la nacionalidad del país de residencia y convivir con otras religiones y culturas, pero sin por ello renunciar a la etnicidad. En este artículo reviso cinco estrategias puestas en práctica para legitimar socialmente a la colectividad judía argentina siguiendo esta tercera política, la liberal. Los agentes involucrados con las cinco estrategias son distintos actores del campo judío (entendiendo campo en el sentido de Bourdieu), entre quienes sobresalen los líderes étnicos, aunque la lista también incluye a intelectuales, artistas y productores de medios masivos de comunicación. Intentaré sostener la hipótesis de que esas estrategias formaron parte de una política identitaria en el sentido de Mendelsohn.

La elección de un período largo, de un siglo de duración, me permite mapear la puesta en acto de esta política en coyunturas y momentos muy diferentes, durante los cuales las relaciones entre los judíos, la sociedad nacional y el Estado argentino experimentaron cambios y transformaciones relevantes. El punto de partida, ubicado en 1910, coincide con la aparición de Los gauchos judíos, el libro de acerca de la vida en una colonia agrícola entrerriana con el que el joven Alberto Gerchunoff logró su consagración literaria. Publicado desde 1908 como folletín en La Nación y lanzado dos años más tarde en formato de libro, sus relatos breves han sido interpretados por distintos investigadores como una apología de la nacionalización de los judíos de la Argentina por la vía del criollismo y del telurismo (Viñas, 1982; Senkman, 1983), en la que los protagonistas devienen argentinos electivos al asimilarse a la cultura rural local. ${ }^{1}$ La fecha de culminación del período (2010) coincide con un evento menos

\footnotetext{
${ }^{1}$ No obstante, también existen otras interpretaciones, que ven al libro como una reafirmación de la etnicidad judía y como una suerte de oda al multiculturalismo, como por ejemplo en Edna Aizemberg (2000), Perla Sneh (2007 y 2010) y James Hussar (2008 y 2011). En mi investigación doctoral (Cherjovsky, 2017) presento ambas versiones y planteo que la convivencia de capítulos asimilacionistas
} 
estudiado hasta la fecha: la salida al aire del personaje televisivo Kosher Waters, interpretado por el comediante Diego Capusotto en la pantalla de la TV Pública argentina (en rigor, el personaje apareció ya en 2009). Kosher Waters es una parodia, en versión judeo-ortodoxa, de Roger Waters, cantante y líder de la archiconocida banda de rock británica Pink Floyd. Lo interesante del caso es que, a lo largo de los distintos episodios, este cantante ortodoxo y roquero interpreta distintas canciones populares con letras apócrifas, que describen rasgos identitarios de los judíos argentinos, proyectando una mirada positiva e integradora: lejos de parecer un otro cultural exótico, Kosher Waters baila y toca la guitarra eléctrica como cualquier joven que gusta del rock, habla y gesticula como un porteño de pura cepa y, de acuerdo con algunas de las letras de las canciones parodiadas, se muestra plenamente integrado a sus conciudadanos no judíos. En una palabra, el sketch funciona como la imagen inversa de Los gauchos judíos, ya que deja entrever que, por debajo del traje negro, el sombrero y los aladares, existe un auténtico argentino. Aquí entiendo a esa transformación como el producto o la consecuencia de un largo proceso histórico en el que se pusieron en práctica estrategias de legitimación.

En el próximo apartado presento las cinco estrategias que detecté hasta el momento. Luego, realizo un breve repaso histórico por los distintos contextos en los que la legitimidad de los judíos fue puesta en tela de juicio por distintos sectores de la sociedad que pusieron en circulaciones mitologías e imágenes negativas. Finalmente, retomo las cinco estrategias para desarrollar mis argumentos en extenso y para mostrar ejemplos de su materialización y puesta en práctica.

\section{Cinco estrategias legitimantes}

Utilizo el concepto de legitimidad ${ }^{2}$ (o legitimación, lo que implica, como dije, un proceso) para referirme a las necesidades de aceptación o reconocimiento (Taylor, 2009) que suelen manifestar las minorías asentadas en sociedades multiculturales,

con otros que reivindican el derecho a la etnicidad representó una estrategia legitimante pensada por Gerchunoff.

${ }^{2}$ De acuerdo con la teoría weberiana, la legitimidad es un elemento clave en la relación de dominación que ejerce el estado sobre los subordinados, en tanto implica la aceptación de sus designios a partir de tres tipos de justificaciones: las basadas en la tradición, en el carisma del líder o en la legalidad de los actos (Weber, 1946). 
especialmente cuando dichas sociedades son de matriz asimilacionista. En ese tipo de casos, la legitimación puede concebirse como una construcción efectuada "de abajo hacia arriba", esto es, como el efecto de una serie de prácticas y representaciones puestas en circulación por los subalternos para ser leídas por quienes determinan la cultura hegemónica o adscriben a ella como mensajes que refrendan la aceptación de los valores y símbolos oficiales, pero que, al mismo tiempo, sostienen la continuidad de la identidad étnica o minoritaria (véase al respecto el trabajo de Bodnar para los casos de distintas minorías en Estados Unidos, 1992).

En el caso concreto que planteo, proponer la existencia de estrategias legitimantes lleva implícita la hipótesis de que el colectivo judío no obtuvo su condición de minoría argentina-no-católica-legítima pasivamente, esperando el dictamen favorable de las élites o aguardando el advenimiento del paradigma multiculturalista, arribado al país durante la reapertura democrática y, en especial, desde los años noventa. Ni que la legitimación se materializó por decantacón, con el simple paso del tiempo, es decir, por el mero hecho de que las nuevas generaciones hubieran nacido y se hubieran educado en el país, consintieran los matrimonios exogámicos, cohabitaran en forma integrada con otros grupos de la sociedad o ejercieran la buena vecindad en los barrios, en el trabajo y en la escuela.

Obtener el reconocimiento en la Argentina del crisol de razas implicaba, sobre todo, despejar toda duda respecto de los sentimientos de pertenencia a una nación extranjera, de los que eran sospechados los judíos (es decir, de su adscripción al proyecto sionista); pero, también, mostrar que ciertos estigmas muy difundidos, como la presunta improductividad y el afán de lucro, eran un asunto del pasado. Finalmente, implicaba presentar las diferencias religiosas y culturales con la mayoría católica como algo anecdótico o folclórico, que no produciría interferencias con los valores dominantes en la sociedad nacional.

Admito que algunas de las evidencias históricas que he encontrado hasta la fecha son fragmentarias y dispersas pero, aun así, creo que resultan suficientes como para plantear que existió una participación activa (y a veces organizada y consensuada) de distintos líderes comunitarios, artistas e intelectuales, quienes pusieron en práctica las siguientes estrategias legitimantes: 
1. La creación de una memoria colectiva judeo-argentina basada en la experiencia de los colonos agrícolas arribados desde 1889, mayoritariamente como parte del proyecto de la Jewish Colonization Association. De acuerdo con esta versión del pasado, los inmigrantes judíos son presentados como sujetos que llegaron al país con el afán de productivizarse y de aportar con su esfuerzo a la concreción del proyecto de la “Argentina granero del mundo". En la versión más romantizada, inaugurada por Gerchunoff en la época del Centenario argentino, se los representaba experimentando un proceso de homogeneización identitaria, como ya he mencionado.

2. La postulación de la existencia de "sangre judía" temprana en las venas argentinas, apoyada en las evidencias acerca de la presencia de marranos o criptojudíos durante la época colonial, mucho antes de la conformación política de la Argentina independiente, presencia que fue ocultada o elidida por el relato histórico oficial de la nación. Lo interesante de esta estrategia es que propone que varios de los principales próceres y grandes hombres argentinos del siglo XIX tuvieron antepasados judíos.

3. La difusión pública de los aportes judíos al progreso del país, sea que éstos se midan en empresas, en bienes exportables o en los logros alcanzados por personalidades del mundo de la ciencia, el arte, el deporte, la política, los medios y la cultura. Existe una verdadera obsesión por conformar listas de judíos destacados y difundirlas.

4. La exacerbación del patriotismo nacionalista, plasmada sobre todo en algunas de las efemérides nacionales más importantes. Esto no quiere decir que la comunidad judía argentina no sostenga sentidos de pertenencia nacionales, o que su participación en las efemérides argentinas sea pura impostación. En absoluto. Pero he detectado que algunas de las grandes efemérides fueron interpretadas por la dirigencia como ocasiones propicias para enviar un mensaje a sectores de la sociedad que cuestionaban la argentinidad de los judíos.

5. La mirada benigna sobre los judíos que fue plasmada en películas, en la prensa y en emisiones radiales y televisivas. Es decir, en diferentes dispositivos creados por la cultura de masas nacional. Esa mirada positiva se relaciona, en muchos casos, con la presencia abrumadora de empresarios, guionistas, productores, locutores y actores que, desde sus lugares, terciaron para modelar los estereotipos judíos que circulaban en el ámbito local, ya sea presentándolos como sujetos integrados a la esencia del ser 
nacional, que transmitían valores positivos, o bien mostrando, como contracara, una mirada crítica sobre el antisemitismo.

\section{La necesidad de legitimación: una perspectiva histórica}

Más adelante me extenderé respecto de estas cinco estrategias. Antes, conviene realizar un breve recorrido histórico que sustente la idea de que, en determinados momentos, algunos sectores de la sociedad consideraron a los judíos ciudadanos ilegítimos.

En efecto, afirmar que, al menos hasta la llegada del paradigma multiculturalista, la presencia judía fue cuestionada desde distintos sectores, incluidos algunos ámbitos del Estado, y, sobre todo, sopesar en qué medida, merece al menos una fundamentación histórica. Especialmente porque tal afirmación podría parecer contradictoria con el hecho palmario de que la Argentina impulsó la llegada de inmigrantes como parte central de su proyecto modernizador, que promulgó la Libertad de Cultos en la Constitución Nacional de 1853, que invitó a los judíos a establecerse en el país oficialmente mediante un decreto presidencial firmado por Julio A. Roca en 1881 y que dispuso que la educación fuera laica al promulgar la Ley de Educación Común 1420. Además, durante el período analizado, el asociacionismo étnico, incluyendo a numerosas instituciones abiertamente sionistas, nunca fue prohibido ni combatido (a diferencia de lo sucedido en otros contextos nacionalistas cercanos, como el Estado Novo de Getulio Vargas) ${ }^{3}$. Además, podría argumentarse que los ciudadanos judíos se han integrado en casi todas las esferas de la vida social y profesional sin mayores obstáculos, llegando a detentar posiciones importantes en la cultura, la política, el deporte y el empresariado, dando vida a la colectividad judía más numerosa y visible de Latinoamérica.

No obstante, a lo largo de distintas coyunturas, los judíos fueron señalados como una parte indeseable del crisol de razas argentino. La literatura académica referida a su historia en el país muestra varias oscilaciones entre signos de aceptación y rechazo. ${ }^{4}$

\footnotetext{
${ }^{3}$ Véase Lesser, 1988.

${ }^{4}$ Esa actitud dual por parte del Estado y de la sociedad argentina, que oscilaba entre la aceptación y el rechazo según las distintas coyunturas, quedó reflejada en los títulos de algunos trabajos académicos:
} 
Según la interpretación de Leonardo Senkman (2007), durante la era liberal, entre fines del siglo diecinueve y comienzos del veinte, la colectividad vivió una suerte de belle époque en la que primaba la idea iluminista de anteponer la ciudadanía al concepto romántico de la nacionalidad. Aunque el planteo de Senkman se verifica en la resolución favorable de numerosos reclamos llevados adelante por ciudadanos judíos ante las autoridades estatales, o bien en ciertas disposiciones que muestran una voluntad inclusiva e integradora, también es cierto que en aquéllos años hubo algunos síntomas de rechazo. Por ejemplo, cuando el flujo migratorio comenzó a masificarse, la novela La bolsa (1891), de José María Miró (publicada bajo el seudónimo de Julián Martel) instaló en el imaginario local el mito de una presunta conspiración judía mundial que buscaba tomar el poder mediante la banca y las finanzas. Lejos de pasar desapercibido, más tarde el libro se convertiría en un clásico de la literatura nacional. Además, algunos funcionarios estatales ubicados en puestos clave, como el comisario de inmigración Juan Alsina, se mostraban refractarios a recibir judíos por considerarlos "indeseables" e "inasimilables".

A partir de la época del Centenario (1910), cuando la Argentina comenzó a preocuparse por afirmar su propia nacionalidad, la identificación de los judíos con la izquierda y con el marxismo provocó algunos desencuentros relevantes. En 1919, durante la represión obrera conocida como la Semana Trágica, la policía salió a la caza de judíos "maximalistas" (es decir, comunistas) organizando un pogromo que dejó varios muertos y heridos, así como evidencias sobre judíos torturados y sobre daños materiales producidos en el barrio del Once, donde residían numerosas familias, comercios e instituciones judías. Más tarde, a lo largo de la década del treinta, las publicaciones de grupos nacionalistas y filo-nazis, algunas de las cuales recibían los beneficios de la publicidad estatal, alentaron abiertamente el antisemitismo de sus lectores al señalar a los judíos como agentes del imperialismo, sea norteamericano, soviético o sionista. Durante aquéllos años, los judíos comenzaron a ser rechazados en algunos clubes sociales y deportivos, e incluso hubo algunos profesores desafectados de las universidades. En la misma época, el gobierno clausuró momentáneamente algunas escuelas judías de orientación comunista, aunque alegando problemas de 
higiene. Tendiendo un puente con La bolsa, una de las novelas más populares en aquéllos años de entreguerras fue la saga El Kahal-Oro (1935), de Gustavo Martínez Zuviría (publicada bajo el seudónimo Hugo Wast), que volvía a reflotar el mito conspirativo de la dominación mundial. Para responder a esa coyuntura problemática, en 1935 las instituciones comunitarias judías dieron vida a la Delegación de Asociaciones Israelitas de la Argentina (DAIA), que desde entonces se transformó en la representante política natural de los judíos ante el Estado nacional.

Durante el primer peronismo, la colectividad judía experimentó sensaciones contradictorias. Por un lado, al reabrir las puertas de la inmigración en el marco del Primer Plan Quinquenal, el régimen de Perón prohibió el ingreso de judíos, explicitando su predilección por los inmigrantes de origen latino. Además, pese a contar con la comunidad judía más numerosa de América Latina, la Argentina fue uno de los pocos países de la región que se abstuvo en la votación por la partición de Palestina, llevada a cabo en 1947, en las Naciones Unidas. Sin embargo, como ha mostrado el historiador Raanan Rein, en otros aspectos el peronismo tuvo gestos de acercamiento hacia los judíos, como el inicio de salutaciones públicas oficiales por las festividades religiosas, el reconocimiento de Israel como una nueva nación en 1948, el inicio de relaciones diplomáticas y comerciales con dicho país, la expulsión del gobierno de funcionarios antisemitas pertenecientes a la Alianza Libertadora Nacionalista y los vínculos personales del líder con los dirigentes de la Organización Israelita Argentina, una institución que representaba a los judíos peronistas. Perón incluso cultivó una larga amistad personal con Luis Elías Sojit, un relator radial de deportes de gran popularidad y de reconocido origen judío. Además, cuando el régimen se apropió del diario La Prensa, el poeta Israel Zeitlin (más conocido como César Tiempo) fue nombrado director del suplemento cultural. De acuerdo con Rein, Perón quería atraer a todos los grupos de la sociedad civil hacia su movimiento, sin importar a qué cultura pertenecieran ni qué religión profesaran; además, veía en su acercamiento a los judíos una forma de quitarse la etiqueta de nazi que querían imponerle en la posguerra desde los Estados Unidos (Rein, 2007).

En los años sesenta, una nueva coyuntura puso en tela de juicio la argentinidad de los judíos, desatando una oleada de atentados organizados por grupos ultranacionalistas: la captura (o secuestro, según qué actor social interpretaba el hecho) del criminal de guerra nazi Adolf Eichmann, efectuada por parte de un comando del servicio secreto 
israelí en mayo de 1960. Eichmann residía en la localidad bonaerense de San Fernando y poseía un documento de identidad argentino emitido por el Estado que lo identificaba como Ricardo Klement. Justamente, con el pretexto de que se trataba de un ciudadano argentino legal, el Movimiento Nacionalista Tacuara y Guardia Restauradora Nacionalista organizaron atentados de diverso tenor, desde agresiones a sinagogas y a sedes institucionales con bombas de alquitrán hasta resonantes casos policiales, como el secuestro de la joven Graciela Sirota, efectuado en 1962, y el asesinato a sangre fría del militante comunista Raúl Alterman, ocurrido en la puerta de su casa el 29 de febrero de 1964.

Otra coyuntura fuertemente marcada por el antisemitismo tuvo al gobierno de facto como protagonista. Durante la última dictadura militar (1976-1983), aproximadamente un diez por ciento de los detenidos-desaparecidos registrados por la Comisión Nacional Sobre la Desaparición de Personas (CONADEP) fueron ciudadanos de origen judío, lo que implica una sobrerrepresentación de diez a uno, ya que en esos años la comunidad conformaba aproximadamente el uno por ciento de la población total del país. Además, existen evidencias de la excesiva saña que mostraban los militares al torturar a detenidos judíos, tal como quedó explicitado en Preso sin nombre, celda sin número, el célebre testimonio publicado por Jacobo Timerman en 1981.

En definitiva, ya sea por prejuicios religiosos o seculares, o bien por considerarlos un colectivo inasimilable, los judíos fueron uno de los grupos migratorios más resistidos de la historia argentina. ${ }^{5}$

\section{Cinco estrategias puestas en práctica}

Volvamos a las cinco estrategias legitimantes. Aquí me referiré con mayor detalle a cada una de ellas y pondré algunos ejemplos históricos que den carnadura real a mi hipótesis. La primera de ellas consiste en la creación de una memoria colectiva judeoargentina basada en la experiencia de los colonos agrícolas arribados desde 1889 . He desarrollado este tema en extenso en mi tesis de doctorado para la Universidad de Buenos Aires, que publiqué en 2017 como Recuerdos de Moisés Ville. La colonización agrícola en la memoria colectiva judeo-argentina (1910-2010) (UAI-Teseo). En ese

\footnotetext{
${ }^{5}$ Sobre estas coyunturas, puede consultarse los siguientes trabajos: Senkman, 1983b; Lvovich, 2003; Senkman y Schnaider, 2005; Avni, 2005.
} 
trabajo, planteo que la elaboración de un pasado local focalizado en el asentamiento de colonos agrícolas en zonas rurales ayudó a construir una imagen positiva de los inmigrantes judíos, alejada de los estigmas del comercio, la usura y la improductividad, así como distante de la presencia de una mafia judía de tratantes de blancas que operaba en el país. Apoyadas en elementos reales, aunque muchas veces distorsionados y presentados en forma grandilocuente o apologética, las representaciones legitimantes se volcaron en numerosos lieux de mémorie, que incluyen literatura, cine, conmemoraciones públicas, libros conmemorativos y monumentos.

Uno de los aspectos más destacables de esa memoria, que resalta el origen rural y minimiza el peso de la numerosa inmigración urbana y la presencia de judíos sefaradíes y orientales, quienes no iban a las colonias, es que la elección del aniversario de la comunidad judía en el país coincide con la fecha de la llegada del Weser, el vapor alemán que trajo a los fundadores de Moisés Ville en agosto de 1889.

Sin embargo, se estima que para entonces ya vivían en la Argentina unos mil quinientos judíos. Podría argumentarse que la elección de una fecha que simbolice los inicios de la vida de determinada comunidad, requiere la existencia de algún hecho histórico relevante, y que, a falta de ese hecho, los emprendedores de la colectividad optaron por un evento tardío, pero significativo, ya que en el Weser llegaron más de ochocientos inmigrantes que fundaron una colonia e influyeron en el aumento del flujo judío a posteriori. Sin embargo, una fecha alternativa (y que incluso alguna vez fue celebrada, pero con mucho menos énfasis) habría sido la de la creación de la primera institución judía en la historia del país. En efecto, la Congregación Israelita de la República Argentina (CIRA) había sido creada en 1862, veintisiete años antes de la llegada del Weser, y formalizada en 1868. Luego, en 1875, la CIRA ya contaba con una pequeña sinagoga ubicada en la calle Artes 351. En 1882, su rabino, Henry Joseph, fue reconocido como tal por el Consistoire francés. Otra fecha posible para anclar la memoria judeo-argentina en un origen preciso podría haber sido el seis de agosto de 1881, cuando el presidente Julio A. Roca firmó un decreto por el cual el gobierno encomendaba a uno de sus funcionarios dirigir hacia el país a los judíos que emigraban masivamente del imperio ruso. 
De acuerdo con los datos que pude recabar, la elección de la llegada del Weser como fecha iniciática de la vida judía en el país tuvo lugar durante la organización de los festejos por el cincuentenario de la colonización judía, llevados a cabo en Moisés Ville a fines de 1939. En esa ocasión, la DAIA publicó un libro conmemorativo titulado 50 años de colonización judía en la Argentina, aparecido en dos versiones (ídish y castellano), en el que varios autores revisaban la historia de la colonización y rendían homenaje a sus protagonistas. Uno de los principales autores fue José Mendelson (1891-1969), un inmigrante llegado al país en 1912, que se había desempeñado como maestro y director de una escuela de la JCA en Palacios, para luego instalarse en Buenos Aires, donde tuvo una destacada actuación en el mundo educativo y cultural judeo-porteño. Sumando los dos artículos que aportó, Mendelson contribuyó con cien de las trescientas páginas del libro. En su artículo titulado "Génesis de la colonia judía en la Argentina (1889-1892)", Mendelson se refiere a la inmigración judía previa a 1889 como la "prehistoria": un período que incluyó a los marranos de la época colonial y a los inmigrantes llegados luego de la independencia argentina del centro de Europa y del norte de África. La idea de que los marranos fueran "prehistóricos" obedecía a que conformaban una rama descontinuada, que se había asimilado y diluido sin dejar "rastros vivientes", al igual que las migraciones de judíos centro-europeos llegados antes del Weser, que por más que hubiesen dejado descendientes vivos habían sido realizadas de manera casual, aislada y sin ninguna finalidad determinada. Esta alteración cronológica ad-hoc no privó a Mendelson de consignar que, aunque prehistóricos, aquéllos judíos previos a la llegada del Weser habían acumulado algunos méritos patrióticos: lucharon en las guerras de la Independencia, enfrentaron a Rosas en Caseros y pelearon en la Guerra del Paraguay, "aportando su sangre como soldados, como oficiales y jefes superiores", e incluso como generales. Si sus nombres no aparecían publicados en el texto era porque se trataba de un tema que requería ser investigado más adelante, con mayor exhaustividad. ${ }^{6}$ Encontré un antecedente de esta idea de acerca de la existencia de una prehistoria judeo-argentina como forma de poner en primer plano la llegada del Weser en un artículo publicado por el historiador Boleslao Lewin (1908-1988, radicado en la Argentina en 1937) en un libro conmemorativo lanzado por el periódico Di Idishe Tzaitung unos meses antes de la

\footnotetext{
${ }^{6}$ El único caso trabajado a posteriori por la historiografía es el del sargento, luego capitán, Luis H. Brie, un judío nacido en Hamburgo y luego nacionalizado argentino que peleó en Caseros, en el ala brasilera de las tropas de Urquiza, y que se radicó en Buenos Aires, donde fue cofundador de la CIRA.
} 
salida del libro de la DAIA, también en 1939. Allí, Lewin había propuesto una cronología conformada por cuatro etapas: la Prehistoria, la Historia Colonial, el "Lapso que termina con la llegada de la inmigración en masa" (sic) y la Historia Contemporánea. ${ }^{7}$

Sintomáticamente, a comienzo de los años cincuenta, cuando en la Argentina comenzó a declinar el número de judíos asentados en el campo, algunos activistas comunitarios preocupados por lo que significaba esa pérdida en términos de legitimidad organizaron un proyecto consistente en la creación de colonias suburbanas, establecidas en las inmediaciones de la localidad bonaerense de Mercedes, con el fin de que familias judías urbanas de pocos recursos ingresaran en el mercado de los cultivos de chacra. Como si fuera una réplica en escala reducida del proyecto del barón Hirsch, esos nuevos chacareros judíos podrían encausar económicamente sus vidas al mismo tiempo que cumplían con una noble finalidad: demostrar al resto de la sociedad que la colectividad tenía una importante base productiva dedicada al trabajo de la tierra. Para una mirada más completa respecto de los usos del pasado colono como mecanismo legitimante, pude consultarse mi propio trabajo (Cherjovsky, 2017).

Ahora veamos un ejemplo del segundo mecanismo, consistente en la postulación de la preexistencia judía, es decir, en la construcción de un discurso que afirma que los judíos arribaron al país antes de la conformación de la Argentina independiente. Este mecanismo, que podría pensarse como la antítesis del argumento de Mendelson, ya que pone en valor aquélla prehistoria que no había dejado rastros vivientes, se apoya en la existencia de documentos fragmentarios, pero que prueban la presencia de criptojudíos durante la época colonial (aunque una versión más audaz se remonta a la era precolombina, y asocia a las culturas indoamericanas con las tribus perdidas de Israel, argumentando que ciertos símbolos y lexemas tienen una similitud o una raíz hebrea). ${ }^{8}$

Entre los autores más prolíficos dentro de esta línea de investigación se encuentran Mario Javier Saban y Mario Eduardo Cohen. Se trata de dos emprendedores altamente

\footnotetext{
7 "Prehistoria e historia colonial de los judíos en la Argentina", en Homenaje a El Diario Israelita con motivo del XXV $V^{o}$ aniversario. 1914-1939.

${ }^{8}$ Véase al respecto el trabajo de Ricardo Feierstein Historia de los judíos argentinos (1999, Ameghino), uno de los libros más difundidos acerca de la historia de la colectividad judía en el país, cuyo capítulo 1 recopila teorías acerca del origen precolombino y marrano.
} 
calificados, dedicados al estudio y la difusión de la historia de los sefardíes en el país y la región, tanto en tiempos de la colonia como de la república. Saban publicó, entre otros trabajos, Judios conversos. Los antepasados judios de las tradicionales familias argentinas (Distal, 1990). Cohen, quien ejerce el cargo de director del Centro de Investigación y Difusión de la Cultura Sefardí, también es autor de varios trabajos, entre los que destaca uno que lleva un título casi idéntico: Judíos conversos. La influencia hebrea en los orígenes de las familias tradicionales argentinas (Sudamericana, 2007), donde, como Saban, rastrea los antepasados criptojudíos de familias de la élite, como por ejemplo los Pueyrredon, quienes habrían sido descendientes de un hombre acusado por la Inquisición de profesar el judaísmo a mediados del siglo XVII. Entre las figuras centrales de la historia argentina que habrían tenido sangre judía se encuentran Rivadavia, Sarmiento, Rosas, Alvear y Urquiza, además de José Hernández, el premio Nobel de Química Federico Leloir y el escritor Jorge Luis Borges. El argumento que descansa en el fondo de este tipo de trabajos se apoya en una presunción biologicista de la identidad, basada en la metáfora de la sangre. Como ha mostrado Ana María Alonso (1994), el tropo de la sangre compartida, o bien, del parentesco biológico, ha sido una de las tres estrategias metafóricas utilizadas para crear identidades a fin de sostener procesos de comunalización (Brow, 1990). Las otras dos son la cohabitación en un territorio compartido y la existencia de un pasado común. Esa idea general acerca de las raíces judías de la sociedad argentina puede entreverse en las conclusiones de uno de los trabajos publicado por Cohen:

"desde su fundación, Buenos Aires y toda la Argentina de entonces, fueron lugares de acogida de los llamados portugueses, algunos de ellos seguramente criptojudios (las crónicas se cansan de señalarlo). Éstos formaron la sociedad raigal porteña, desde su más lejano origen." (Cohen, 2008: 35)

El tercer mecanismo consiste en la difusión de los aportes judíos al progreso del país, materializados generalmente en personalidades del mundo de la ciencia, el arte, el deporte y la cultura. A veces esos aportes también pueden referirse a productos concretos: en mi trabajo sobre la memoria de la colonización he detectado un afán por difundir la producción agrícola-ganadera de los colonos judíos mediante números, 
fotos y tablas estadísticas. Por ejemplo, un documental sobre las colonias filmado en 1925 por la compañía cinematográfica de Max Glüksmann, pionero del cine en el país y líder comunitario, informa a los espectadores sobre las toneladas de los distintos productos que fueron producidas por los colonos ese año. En esa misma línea, en 1976, la Oficina Sudamericana del Comité Judío Americano publicó Aportes de la colonización agraria Judía a la economía nacional, un libro escrito por el prolífico emprendedor comunitario José Liebermann. Aquí me referiré a otro fenómeno interesante: las publicaciones que compilan listados de judíos destacados, en las que se realzan sus méritos y aportes al progreso de la nación, o simplemente su condición de estrellas del espectáculo o de famosos. Por ejemplo, en Judios \& Argentinos. Homenaje al centenario de la inmigración judía en la Argentina/1889, el libro conmemorativo que acompañó los festejos por el centenario (celebrado en 1989, siguiendo la tradición inaugurada en 1939 que, como vimos, databa los inicios de la vida judía en el país en relación con la llegada del Weser), varias de las secciones están dedicadas a repasar la presencia de ciudadanos judíos en el arte, las ciencias, el deporte, la economía, la política y otras esferas de la vida pública. Del mismo modo, en el ya aludido Historia de los judíos argentinos (Ameghino, 1993), de Ricardo Feierstein, el capítulo 9, de más de cincuenta páginas de extensión, también está dedicado a este tema. A veces, en el afán de encontrar judíos destacados, este tipo de trabajos incurre en lo que podríamos llamar "conversiones inconsultas", al señalar a personalidades como David Lebón o Pipo Pescador como integrantes de la colectividad. En el caso del guitarrista de rock David Lebón, de destacada trayectoria en bandas como Pappo's Blues, Pescado Rabioso y Serú Girán, el equívoco se debe a que su apodo es "el Ruso", típica forma de llamar a los judíos en la Argentina (y que también se usa para aludir a personas rubias, especialmente en las provincias). Incluso Charly García, cantante y líder de Serú Girán, la banda de rock más importante de la historia argentina, solía bromear desde el escenario diciéndole, con un teléfono en la mano, "David, teléfono desde Tel Aviv". Sin embargo, Lebón, cuyo apellido es vascofrancés, no es judío, como puede leerse en distintas entrevistas y hasta en Wikipedia. Algo similar sucede con el célebre músico y actor Pipo Pescador, cuyo nombre real es Enrique Fischer. En este caso, la confusión probablemente se deba a la sonoridad del apellido y al origen entrerriano (en las colonias agrícolas que estableció en Entre Ríos la compañía de Hirsch se radicaron muchos inmigrantes judíos), pero lo cierto es que Fischer es descendiente de alemanes del Volga. Estas judaizaciones inconsultas 
muestran cierta necesidad de los emprendedores culturales de ponderar las virtudes del colectivo judío resaltando la pertenencia de artistas y personalidades célebres, a fin de legitimar a la colectividad en su conjunto.

El cuarto mecanismo legitimante consiste en la exacerbación del patriotismo nacionalista, plasmada sobre todo en ocasión de las efemérides nacionales más importantes. Aquí voy a poner otro ejemplo que conozco bien por haberlo investigado para un capítulo del libro Identidades, Memorias y Poder Cultural en la Argentina (siglos XIX al XXI) (Bjerg y Cherjovsky compiladores, UNQ 2019, en prensa). En 1950, al cumplirse los cien años de la muerte del general San Martín, el presidente Juan Domingo Perón decretó la conmemoración del año sanmartiniano y organizó una serie de festejos fastuosos, que incluyeron la presencia de delegaciones militares enviadas por los países liberados por el prócer y que lo tuvieron a él mismo como protagonista del acto central, al hacer sonar la campana de Huaura -una reliquia militar traída especialmente desde Perú- a la hora exacta en que se había producido la muerte del Libertador, el día 17 de agosto. En ese clima, numerosas instituciones, empresas y organizaciones civiles se sumaron a la conmemoración, realizando por lo general ofrendas florales y colocando placas en los distintos monumentos que recordaban a San Martín. Por supuesto, las colectividades de inmigrantes también se hicieron presentes en el espacio público para refrendar su nacionalidad argentina. Sin embargo, si se comparan sus actuaciones, la performance de la colectividad judía es por lejos la más notable. Entre otras actividades, a lo largo del año, la DAIA organizó un verdadero tour conmemorativo que incluyó la colocación de placas y ofrendas florales en las distintas ciudades en las que residían comunidades judías organizadas. En el monumento al ejército de los Andes, ubicado en el Cerro de la Gloria, Mendoza, la DAIA colocó una placa esculpida por Israel Hoffman en la que se observaba un paralelismo entre dos libertadores: San Martín levantando su espada y Moisés levantando las Tablas de la Ley. La DAIA también publicó un libro titulado San Martín y los principios morales del judaísmo, del emprendedor cultural Lázaro Schallman, quien se dedicó a compilar meticulosamente todas las frases escritas por San Martín que permitían establecer una relación intertextual con los libros sagrados judíos. Uno de los capítulos, por ejemplo, comparaba la vida del prócer con la de Judas Macabeo, el líder nacionalista judío del siglo II AC. Pero el argumento más fuerte del libro era otro capítulo, en el que Schallman publicitaba la estrecha amistad de San 
Martín con el banquero español Alejandro María de Aguado, quién había solventado económicamente al prócer (además de a su hija y a su yerno) durante los últimos años de su vida, cuando se encontraba en la bancarrota, en Francia. Lo importante en relación con esta amistad es que, de acuerdo con Schallman, Aguado era judío. En realidad, Aguado había sido bautizado como católico y, aunque proviniera de una familia de criptojudíos portugueses, probablemente jamás se haya imaginado a sí mismo como un judío. Pero un célebre intelectual español contemporáneo de Schalmann, Gregorio Marañón, había publicado en un apartado de uno de sus libros que le parecía que los Aguado descendían de una familia criptojudía. Esa breve nota fue suficiente para que Schallman y otros emprendedores e intelectuales judíos se lanzaran a dictar conferencias y a publicar notas en revistas y periódicos acerca del amigo judío que había salvado a San Martín en sus años de auto-exilio. ${ }^{9}$ El año pasado dicté una conferencia sobre este tema en un espacio de difusión de temas judíos llamado Limud BA, que se realiza todos los años en la ciudad de Buenos Aires. Al finalizar la disertación, uno de los asistentes vino a decirme que, aunque le había gustado mi charla, estaba un poco triste porque, de chico, su padre le había narrado numerosas veces la historia del amigo judío de San Martín. Este episodio me permitió completar el círculo de esta clase de mecanismos legitimantes: un intelectual crea un dispositivo (en este caso, el mito de que Aguado era judío), luego lo difunde y, finalmente, las familias judías argentinas se lo apropian y lo transmiten a sus hijos para que éstos tengan un buen argumento cuando sus compañeros católicos del colegio, del barrio o del club les hagan algún comentario antisemita. En la película La terraza (Leopoldo Torre Nilsson, 1963), se puede ver una escena en la que dos muchachos antisemitas se quejan porque en una de las facultades de la Universidad de Buenos Aires, done ellos mismos estudian, se dicta una conferencia acerca de Aguado, el amigo judío de San Martín (“Ahora resulta que todo el mundo es judío”, dice con fastidio uno de ellos).

El quinto mecanismo es más complejo de refrendar empíricamente. Consiste la mirada benigna acerca de personajes judíos que difundió la cultura de masas en la Argentina (obviamente, con algunas excepciones, vinculadas especialmente con la prensa

\footnotetext{
${ }^{9}$ Véase también los trabajos de Luis Kardúner: Alejandro Aguado, el bienhechor (1953, Instituto JudíoArgentino de Cultura e Información) y Alejandro Aguado el amigo dilecto del General San Martin en el exilio (1963, Universidad Nacional de Cuyo).
} 
nacionalista del período de entreguerras). En la televisión, el cine, la radio y los medios gráficos se ha presentado generalmente a los judíos como sujetos integrados a la sociedad, poseedores de sentidos de pertenencia nacionales y portadores de valores positivos. Al mismo tiempo, esos medios han denunciado largamente la discriminación y el antisemitismo. Si bien es imposible aducir que detrás de todos los personajes judíos benignos que circularon en la cultura de masas hubo una acción mancomunada, mi hipótesis es que la sobrerrepresentación de productores, empresarios, actores, guionistas, periodistas y locutores judíos en ámbitos como la prensa, el cine, la radio y la televisión, muchos de los cuales incluso detentaron lugares de poder, evidentemente ayudó a terciar en esta suerte de militancia legitimante. Cuando me refiero a sobrerrepresentación y a lugares de poder, quiero decir que el terreno de la cultura de masas fue especialmente fértil para los judíos, y pienso en empresarios como Max Glücksmann, el introductor del cine en el país y dueño de una cadena de setenta salas distribuidas en Latinoamérica; en Jaime Yankelevich, el "zar" de la radio entre el treinta y el cincuenta, cuyos descendientes continuaron con el oficio hasta el día de hoy; en otros dueños de medios, como Alejandro Romay; en editores como Cesare Civitta, cuya Editorial Abril publicó las revistas populares Parabrisas, Corsa, Claudia, Adán, Panorama y Siete Dias Ilustrados. También en Luis Elías Sojit, Adolfo Stray, Paloma Efron-Blackie, los hermanos Sofovich, Cecilio Madanes, Leonardo Simons, Tato Bores, Jorge Guinzburg, Daniel Burman o Axel Kuschevatsky; e incluso en el humorista Roberto Moldavsky, que en 2018 es líder en venta de entradas en los teatros porteños con un espectáculo de humor judío.

Aunque, por sí sola, esa abundancia judía entre las bambalinas de la cultura de masas no me habilita a inferir su participación activa en la legitimación de la colectividad, existen algunos indicios acerca de cierta direccionalidad a la hora de armar los guiones. Uno de esos casos es el de Titanes en el Ring, un show de luchadores de catch de la TV argentina sumamente popular, incluso en otros países de habla hispana, emitido por cuatro décadas desde los años sesenta, que mostraba un mosaico de identidades, ya que muchos de los personajes representaban a distintas nacionalidades. Uno de los titanes era "Tenembaum, el israelí", interpretado por el luchador judío René Tenembaum. Al igual que los demás personajes importantes, Tenembaum, cuyo atuendo incluía una estrella de David en el pecho, tenía un archirrival: el árabe Tufi Memé. A su vez, en Titanes en el Ring había luchadores enrolados en el bando de los 
buenos (un grupo liderado por el armenio Martín Karadagián, líder de la troupe), que enfrentaban a los malos. En el caso de los dos rivales meso-orientales, Tenembaum militaba del lado de los buenos y, Tuffi Memé, del de los malos, tal como quedó refrendado en las letras de las canciones que representaban a ambos personajes, que sonaban mientras ellos caminaban hacia el ring. La canción de Tenembaum decía

"Griten con Tenenbaum, bailen con Tenenbaum, que nos trae recuerdos de Israel; griten con Tenenbaum, canten con Tenenbaum, recordando toda la niñez; griten con Tenenbaum, bailen con Tenenbaum, la alegría va a reinar con él; Tenenbaum es emisario de la Estrella de David".

En cambio, la de su rival decía

"Viene del desierto, trae mucha arena, Tuffi Memé; saca mucho pecho, eso es una pena, Tuffi Memé; no tires arena a los ojos no, no la tires; dicen que es muy limpio, pero juega sucio, Tuffi Memé; sufre cuando pierde, goza cuando pega, Tuffi Memé".

Aunque se trata de un dato difícil de chequear, es muy probable que en la decisión de incluir a Tenembaun entre los buenos y a Memé entre los malos haya influido la célebre Blackie, quien ofició como productora de Titanes en el Ring. La ascendencia judía de Blackie, nacida como Paloma Efrón en una colonia judía entrerriana, era de público conocimiento en el país. Blackie además era hija de Iedidio Efrón, célebre director de la red escolar de la JCA en la Argentina, y siempre se mantuvo involucrada con las cuestiones relacionadas con la identidad judía.

\section{Conclusiones}

Estos fragmentos de materiales muy dispersos que acabamos de revisar, todos ellos relacionados con la historia de los judíos en la Argentina, conforman los retazos de una imagen incompleta, pero que comienza a adivinarse, como un rompecabezas a medio terminar. Allí conviven elementos tan heterogéneos como un clásico de la literatura 
nacional junto a un luchador de Titanes en el Ring, ambos al lado de una pintura rupestre precolombina. Un poco más allá, pero formando parte de la misma escena, aparece un presunto amigo judío de San Martín al lado de Kosher Waters, los dos bien cerca de una colonia agrícola suburbana y, a la vez, de David Lebón y de Pipo Pescador, personalidades de la cultura argentina imaginados como portadores de un judaísmo inexistente. Estos datos, que a primera vista parecen inconexos, al reunirlos, habilitan el tratamiento de un tema que ha estado flotando en el aire de los estudios judíos latinoamericanos, pero que pocas veces ha sido enfocado como un tema en sí mismo, como el meollo de un asunto con vida propia. Se trata de las estrategias puestas en práctica por distintos actores del campo judío de la Argentina para lograr la aceptación dentro del discurso del crisol de razas, un discurso en el que no todos los sectores de la sociedad han estado dispuestos a incluirlos.

\section{Bibliografía}

Aizenberg, Edna (2000) Parricide on the pampa? A new study and translation of Alberto Gerchunoff's Los gauchos judíos, Iberoamericana.

Alonso, Ana María (1994) "The Politics of Space, Time and Substance: State Formation, Nationalism and Ethnicity", Annual Review of Anthropology, Vol. 23 (1994), pp. 379-405.

Avni, Haim (2005) Argentina y las migraciones judías. Milá, Buenos Aires.

Barth, Fredrik (1976) Los grupos étnicos y sus fronteras, Fondo de Cultura Económica, México.

Bjerg, María y Cherjovsky, Iván (2014) "Memoria pública e identidad étnica en el mundo rural de la Argentina. Conmemoraciones locales y fiestas de inmigrantes europeos, 19201940", Estudios Migratorios Latinoamericanos nº 76, julio-diciembre de 2014, PP. 3-26.

Bodnar, John (1992) Remaking America. Public memory, Commemoration, and Patriotism in the Twentieth Century. Princeton University Press, New Jersey.

Brow, James (1990) "Notes on Community, Hegemony, and the Uses of the Past". Anthropological Quarterly 63 (1): 1-6.

Cherjovsky, Iván (2017) Recuerdos de Moisés Ville. La colonización agrícola en la memoria colectiva judeo-argentina (1910-2010), UAI-Teseo, Buenos Aires.

(2019) "San Martín tenía un amigo judío: las minorías en la Argentina y el problema de la legitimidad", en Bjerg y Cherjovsky (compiladores) Identidades, Memorias y Poder Cultural en la Argentina desde 1880 al Siglo XXI, Unidad de Publicaciones del 
Departamento de Ciencias Sociales de la Universidad Nacional de Quilmes, Serie Encuentros, en prensa.

Hussar, James A. (2008) Cycling Through the Pampas: Fictionalized Accounts of Jewish Agricultural Colonization in Argentina and Brazil, tesis doctoral, University of Notre Dame.

(2011) "Los gauchos judíos de Alberto Gerchunoff en su Centenario". The Free Library, revista electrónica (September, 1).

Lesser, Jeffrey (1988) "Continuity and Change within an Immigrant Community: The Jews of São Paulo, 1924-1945", Luso-Brazilian Review, Vol. 25, No. 2 (Winter, 1988), pp. 45-58.

Lvovich, Daniel (2003)Nacionalismo y antisemitismo en la Argentina. Javier Vergara Editor, Buenos Aires.

Mendelsohn, Ezra (1993) On Modern Jewish Politics. Oxford University Press, USA.

Rein, Raanan (2007) Argentina, Israel y los Judíos. Lumiere, Buenos Aires.

Senkman, Leonardo (1983) La identidad judía en la literatura argentina, Buenos Aires, Pardes.

(1989) El antisemitismo en la Argentina, 3 volúmenes. CEAL, Buenos Aires.

(2007) "Ser judío en la Argentina: las transformaciones de la identidad nacional", en Identidades judias, modernidad y globalización (Mendes-Flohr, Paul; Assis, Yom Tov; Senkman, Leonardo, compiladores), Lilmod, Buenos Aires.

Senkman, Leonardo y Sznajder, Mario (1995, compiladores) El legado del autoritarismo. Grupo Editor Latinoamericano.

Sneh, Perla (2007) "Alberto Gerchunoff, entre el nombre y el pronombre", prólogo a la edición deLos gauchos judíos/El hombre que habló en La Sorbona. Colihue y Biblioteca Nacional, colección Los Raros.

(2010) "Alberto Gerchunoff, una lectura bicentenaria". Convergencia $\mathrm{N}^{\circ} 40$.

Taylor, Charles (2009) El multiculturalismo y la política del reconocimiento, Fondo De Cultura Económica, USA.

Viñas, David (1982) Literatura argentina y realidad política. CEAL, Buenos Aires.

Weber, Max (1946) "Politics as a vocation". En H.H. Gerth y C. Wright Mills (traductores y editores) From Max Weber: Essays in Sociology. New York: Oxford University Press. 